\section{Neumonía comunitaria por Proteus mirabilis}

\section{Sr. Director:}

El género Proteus pertenece a la familia de las Enterobacteriaceae y es responsable de infecciones en el ser humano; la especie Proteus mirabilis es la que con mayor frecuencia está implicada. Al igual que otras enterobacterias como E. coli, causa con más frecuencia infección urinaria y cutánea. Está también implicado en septicemia especialmente en pacientes inmuncomprometidos, y ocasionalmente produce infección pulmonar. Se cree que el germen alcanza la vía aérea por inhalación, implicándose el papel de la colonización intestinal como posible reservorio (1). El papel de este como patógeno nosocomial ha sido descrito en varias ocasiones (2). Existe según nuestra información, un único caso de infección comunitaria por éste germen (3). Presentamos a su consideración un nuevo caso asociado a una infección urinaria.

Paciente de 86 años con antecedentes personales de broncopatía crónica (FEV1 50\%), hipertrofia benigna de próstata, portador de sonda uretral permanente en los dos años previos. Ingresa por cuadro sincopal asociado a síndrome febril. Interrogado dirigidamente describe discreto aumento de su broncorrea sin otros síntomas. A la exploración el paciente presenta sobrepeso, temperatura de $39^{\circ} \mathrm{C}$, sin encontrarse subjetivamente afectado, taquipneico (18 rpm) tolerando decúbito. La analítica al ingreso muestra discreta leucocitosis con un $83 \%$ de neutrófilos sin formas jóvenes, e insuficiencia respiratoria (pO2 $55 \mathrm{mmHg}, \mathrm{pCO} 250 \mathrm{mmHg} \mathrm{pH}$ $7,45 \mathrm{HCO} 330 \mathrm{mEq} / \mathrm{L}$ ). El ECG muestra sobrecarga sistólica sobre un ritmo sinusal. La radiografía de tórax no evidencia consolidación. La analítica de orina presenta discreta leucocituria (8 leucos/ campo; en el contexto de un paciente sondado). Se realiza punción lumbar sin alteraciones. Ingresa con la sospecha de traqueobronquitis aguda sin poder descartar infección urinaria. Se envían muestras de hemocultivo, urocultivo, catéter ureteral y esputo al laboratorio de microbiología. Se inicia tratamiento empírico con amoxicilina-Ac. clavulánico. A los tres días de ingreso con el paciente clínicamente mejor, se evidencia en una radiografía de tórax de control, consolidación cavitada en LSD (Fig. 1). El laboratorio de microbiología confirma cultivo positivo para $P$ mirabilis en orina y esputo con sensibilidad al antibiótico en uso, que se mantiene continuando la mejoría clínica y finalmente la radiológica. Se realiza estudio cistográfico que evidencia vejiga de lucha y divertículo vesical gigante sin que se pudiese completar el estudio perimiccional por incapacidad del paciente para orinar. El estudio microbiológico en heces y sangre fue estéril. El paciente es finalmente dado de alta con 02 domiciliario y recuperación completa del cuadro.

El género proteus se ha implicado en patología pulmonar especialmente asociada a pacientes inmunocomprometidos (4) aunque en otras revisiones extensas de bacteriemias asociadas a este germen no se evidencia enfermedad pulmonar primaria (5). La persistencia de Proteus mirabilis en el tracto urinario se debe a su habilidad para causar la formación de litiasis urinaria merced a su capacidad de producción de ureasa que cataliza la urea en $\mathrm{CO} 2$ y amonio, y afectar asimismo a los catéteres urinarios; ambos provén al patógeno de un nicho protector frente al sistema inmune celular y los agentes microbianos. Hay otros factores de virulencia reconocidos en esta especie además de la ureasa, como la hemolisina, flagelos fimbrias y dos proteasas, que producen un fenotipo fácilmente identificable in vitro que permite su clasificación. Otros factores como reguladores de transcripción, enzimas metabólicas, genes de respuesta al estrés y transductores de señal son más difíciles de identificar por lo que se han desarrollado diversas técnicas de identificación para demostrar estos factores patogénicos que parecen estar implicados en su colonización del tracto urinario (6). Posiblemente éstos permitan explicar la posi-

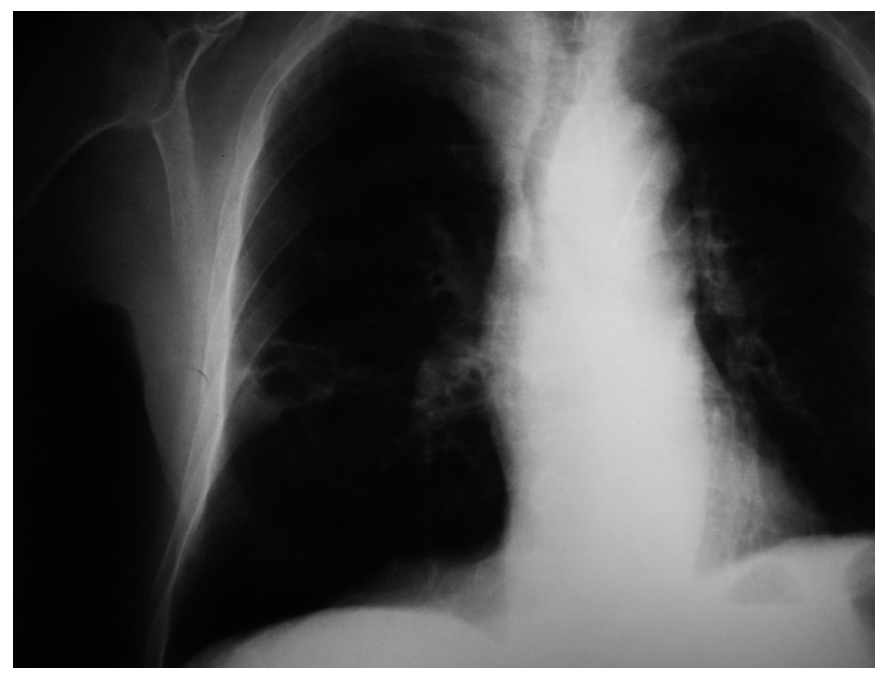

Fig. 1. Rx tórax: consolidación cavidad de LSD.

bilidad de invasión del torrente sanguíneo tras la ruptura de la célula epitelial del túbulo renal y, la posibilidad de realizar esta invasión precozmente, como en el caso que presentamos. Esto nos permitiría entender también otros casos de bacteriemia por proteus, en que no hay afección final del parenquima pulmonar (5). En este caso, la detección del germen en sangre ha sido infructuosa pero creemos que la patogénesis del proceso se asocia con una posible bacteriemia transitoria desde un foco urinario, seguramente en relación al divertículo vesical y/o sondaje vesical permanente, que afecta al parénquima pulmonar dada la coincidencia con la bacteriuria detectada, y no la tradicional vía de adquisición del germen a través de la inhalación directa, por lo que en pacientes con patología urinaria y pulmonar crónicas concomitantes, ha de ser una patógeno a tener en cuenta.

\section{Villamil Cajoto, A. Van den Eynde Collado, M. J. Villacián Vicedo $^{1}$, C. Martínez Rey, L. Rodríguez Otero ${ }^{2}$, M. Rodríguez Framil}

Servicio de Medicina Interna. ${ }^{2}$ Servicio de Microbiología. Hospital Clínico Universitario de Santiago de Compostela. ${ }^{I}$ C. S. Palas de Rey. Lugo.

1. Chow AW, Taylor PR, Yoshikawa TT, Guze LB. A nosocomial outbreak of inffections due to multiply resistant Proteus mirabilis: role of intestinal colonization as a major reservoir. J Infect Dis 1979; 139: 621-7.

2. Luna CM, Monteverde A, Rodríguez C, Apezteguia C, Zabert G, Ilutovich S, Menga G, et al. Neumonía intrahospitalaria: guía clínica aplicable a Latinoamérica preparada en común por diferentes especialistas. Arch Bronconeumol 2005; 41: 439-56.

3. Córdoba A, Monterrubio J, Bueno I, Corcho G. Neumonía comunitaria grave por Proteus mirabilis. Enferm Infeccc Microbiol Clin 2005; 23: 247-50.

4. Tillotson JR, Lerner AM. Characteristics of pneumonias caused by Bacillus proteus. Ann Intern Med 1968; 68: 287.

5. Adler JL, Burke JP, Martin DF, Finland M. Proteus infections in a general hospital. II. Some clinical and epidemiological characteristics. UIT an anaysis of 71 cases of Proteus bacteraemia. Ann Intern Med 1971; 75: 531-6

6. Burral LS, Harro JM, Li X, Lockatell CV, Himpsl SD, Hebel JR, Johnson DE, Mobley HLT Proteus mirabilis genes that contribuye to patogénesis of urinari tract infection: Identification of 25 signature-tagged mutants attenuated at least 100-fold. Infect Immun 2004; 72: 2922-38. 